\title{
Phytohormones and volatile organic compounds, like geosmin, in the ectomycorrhiza of Tricholoma vaccinum and Norway spruce (Picea abies)
}

\author{
Oluwatosin Abdulsalam ${ }^{1} \cdot$ Katharina Wagner $^{1} \cdot$ Sophia Wirth $^{1} \cdot$ Maritta Kunert $^{2} \cdot$ Anja David $^{2} \cdot$ Mario Kallenbach $^{2}$. \\ Wilhelm Boland ${ }^{2} \cdot$ Erika Kothe $^{1} \cdot$ Katrin Krause $^{1}$ (1)
}

Received: 21 June 2020 / Accepted: 11 November 2020 / Published online: 18 November 2020

(c) The Author(s) 2020

\begin{abstract}
The ectomycorrhizospheric habitat contains a diverse pool of organisms, including the host plant, mycorrhizal fungi, and other rhizospheric microorganisms. Different signaling molecules may influence the ectomycorrhizal symbiosis. Here, we investigated the potential of the basidiomycete Tricholoma vaccinum to produce communication molecules for the interaction with its coniferous host, Norway spruce (Picea abies). We focused on the production of volatile organic compounds and phytohormones in axenic T. vaccinum cultures, identified the potential biosynthesis genes, and investigated their expression by RNA-Seq analyses. T. vaccinum released volatiles not usually associated with fungi, like limonene and $\beta$-barbatene, and geosmin. Using stable isotope labeling, the biosynthesis of geosmin was elucidated. The geosmin biosynthesis gene ges 1 of T. vaccinum was identified, and up-regulation was scored during mycorrhiza, while a different regulation was seen with mycorrhizosphere bacteria. The fungus also released the volatile phytohormone ethylene and excreted salicylic and abscisic acid as well as jasmonates into the medium. The tree excreted the auxin, indole-3-acetic acid, and its biosynthesis intermediate, indole-3-acetamide, as well as salicylic acid with its root exudates. These compounds could be shown for the first time in exudates as well as in soil of a natural ectomycorrhizospheric habitat. The effects of phytohormones present in the mycorrhizosphere on hyphal branching of T. vaccinum were assessed. Salicylic and abscisic acid changed hyphal branching in a concentration-dependent manner. Since extensive branching is important for mycorrhiza establishment, a well-balanced level of mycorrhizospheric phytohormones is necessary. The regulation thus can be expected to contribute to an interkingdom language.
\end{abstract}

Keywords Ectomycorrhiza · Tricholoma vaccinum · Norway spruce · Volatile organic compounds · Geosmin · Germacradienol synthase $\cdot$ Phytohormones

Electronic supplementary material The online version of this article (https://doi.org/10.1007/s00572-020-01005-2) contains supplementary material, which is available to authorized users.

Katrin Krause

katrin.krause@uni-jena.de

1 Institute of Microbiology, Microbial Communication, Friedrich Schiller University Jena, Neugasse 25, 07743 Jena, Germany

2 Max Planck Institute for Chemical Ecology, Hans-Knöll-Straße 8, 07745 Jena, Germany

\section{Introduction}

Communication is essential to establish interactions between different cells, individuals, species, kingdoms, and even domains of life in their respective habitats. Forests enhance their stress tolerance to biotic and abiotic factors via the formation of mutualistic mycorrhizal associations between mainly basidiomycete fungi and their host trees (Read et al. 2004). In the mycorrhizosphere, the mycorrhizal fungus interacts with the plant root and the released nutrients of this symbiosis influence the community of associated microorganisms in the soil (Timonen and Marschner 2006). Thus, the specific microbiome associated to a mycorrhizal root differs from that of the surrounding soil, which has led to the framing of this community as ectomycorrhizosphere. It 
can be accessed when soil adhering to an excavated mycorrhizal root is considered. The fungal partner within such an ectomycorrhizosphere is determined by the appearance of the mycorrhizal morphotype (Agerer 1987-2002).

The interaction in a specific ectomycorrhizal community is created by signals bi-directionally sent and perceived between the partners via the water phase as well as by air (Raudaskoski and Kothe 2015). Among those, phytohormones as well as volatile organic compounds (VOC) released to the environment can affect the symbiosis (Effmert et al. 2012). Phytohormones produced by ectomycorrhizal fungi can act in establishing mycorrhiza (Felten et al. 2009; 2012; Laurans et al. 2001; Luo et al. 2009; Splivallo et al. 2009). Evidence for mycorrhiza-modulating factors has been obtained for indole-3-acetic acid (IAA; Gea et al. 1994), salicylic acid (SA; Medina et al. 2003), jasmonates (JA; Hause et al. 2007), and strigolactones (Besserer et al. 2006), all known for their role as plant hormones and presence in fungal mycelia. Among those, SA is involved in plant-pathogen associations and can induce systemic acquired resistance (Audenaert et al. 2002). A volatile phytohormone, ethylene (ET), is a plant defense compound and stimulates lateral root development, mycorrhization, and IAA production in Pinus contorta, Picea engelmannii, and Pseudotsuga menziesii roots (Graham and Linderman 1980; Scagel and Linderman 1998; Splivallo et al. 2009). The production of IAA by Tricholoma vaccinum has been shown already (Krause et al. 2015).

Mono- and sesquiterpenes, aldehydes and alcohols, ketones, esters, organic acids, and aliphatic and aromatic hydrocarbons are represented among VOCs (Macías-Rodríguez et al. 2015). A role for sesquiterpenes emitted by the ectomycorrhizal fungus Laccaria bicolor has been established: they stimulated lateral root growth of the host Populus, and also were able to stimulate root growth in the non-host plant Arabidopsis (Ditengou et al. 2015). Another volatile omnipresent in soils, geosmin, is a major contributor to the petrichor (earth smell) that is observed post-rain fall after a long spell of dryness. This volatile organic compound, trans-1,10-dimethyl-trans-9-decalol, is mainly produced by actinomycetes (Gerber and Lechevalier 1965). Reports of production by other organisms including mold fungi (Kikuchi et al. 1981; Mattheis and Roberts 1992), arthropods (Omura et al. 2002), and red beets (Lu et al. 2003) are available; fungi of the division Basidiomycota were not yet among those. The very low odor threshold (ca. 5-7 ng/L) of geosmin makes the compound to an important off-flavor contaminant of drinking water and bioaccumulates in fish and shellfish leading to a muddy taste (Dupuy et al. 1986).

The biosynthesis pathway of geosmin has been well characterized in bacteria, particularly in the actinobacterial genus Streptomyces. A bi-functional enzyme, germacradienol/ geosmin synthase, has been identified to be specific for biosynthesis of geosmin. The N-terminal domain of the protein converts farnesyl diphosphate (FPP), the immediate precursor of cyclic sesquiterpenes, into germacradienol and germacrene $\mathrm{D}$, while the $\mathrm{C}$-terminal domain catalyzes the transformation of germacradienol to geosmin (Jiang et al. 2007). While the biosynthesis pathway has been settled for actinomycetes, eukaryotic pathways for geosmin biosynthesis are underrepresented. Siddique et al. (2012) reported a P450 monooxygenase (gpel) involved in geosmin biosynthesis in Penicillium expansum. However, a germacradienol/ geosmin synthase has not yet been reported from eukaryotes.

The effects of VOCs as signaling molecules in ectomycorrhizae have not largely been appreciated so far, and phytohormones have not yet been directly shown in a mycorrhizospheric habitat. We thus aimed at identifying plant hormones in the rhizosphere of Norway spruce (Picea abies) associated with the widespread ectomycorrhizal fungus Tricholoma vaccinum (Asiimwe et al. 2012). In addition, the potential of T. vaccinum to produce phytohormones and hormone-like substances, as well as other VOCs, was investigated and the biosynthetic pathway for the production of geosmin in the basidiomycete fungus has been identified. To show the relevance of putative volatile communication molecules in ectomycorrhiza formation and functioning, the effect of exogenous phytohormones was tested in fungal cultures.

\section{Material and methods}

\section{Cultivation of $T$. vaccinum, mycorrhiza, preparation of soil extracts and root exudates}

T. vaccinum GK6514 (FSU4731, Jena Microbial Resource Collection, Germany) grown in 50-mL liquid Modified Melin Nokrans b medium (1 L MMNb: $0.05 \mathrm{~g} \mathrm{CaCl}_{2} \cdot 2 \mathrm{H}_{2} \mathrm{O}$,

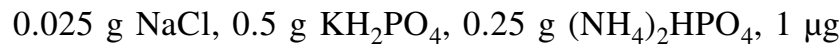
$\mathrm{FeCl}_{3} \cdot 6 \mathrm{H}_{2} \mathrm{O}, 0.15 \mathrm{~g} \mathrm{MgSO}_{4} \cdot 7 \mathrm{H}_{2} \mathrm{O}, 10 \mathrm{~g}$ glucose, $5 \mathrm{~g}$ malt extract, $1 \mathrm{~g}$ peptone from casein, $10 \mathrm{~mL}$ Fortin solution (for $1 \mathrm{~L}: 3.728 \mathrm{~g} \mathrm{KCI}, 1.546 \mathrm{~g} \mathrm{H}_{3} \mathrm{BO}_{3}, 0.845 \mathrm{~g} \mathrm{MgSO}_{4} \cdot 7 \mathrm{H}_{2} \mathrm{O}$, $\left.0.575 \mathrm{~g} \mathrm{ZnSO}_{4} \cdot 7 \mathrm{H}_{2} \mathrm{O}, 0.125 \mathrm{~g} \mathrm{CuSO}_{4} \cdot 5 \mathrm{H}_{2} \mathrm{O}\right), 83 \mu \mathrm{L}$ thiamine hydrochloride $(1.2 \mathrm{mg} / \mathrm{mL}$ stock solution) after Kottke et al. 1987) at room temperature in the dark without shaking for 4 weeks in three biological replicates was used for phytohormone and VOC measurements. Three technical replicates were performed for the measurements. Mycelial biomass $(100 \mathrm{mg})$ of the grown culture from each of the three replicates was ground in liquid nitrogen and stored at $-80^{\circ} \mathrm{C}$. For spruce, Picea abies (Karst.) seeds (Landesforst Mecklenburg-Vorpommern, Germany) were soaked in tap water over night, sterilized in $30 \% \mathrm{H}_{2} \mathrm{O}_{2}$, rinsed, germinated, and grown on germination medium as reported by Krause 
and Kothe (2006). Liquid MMNa medium (differs to $\mathrm{MMNb}$ with $0.5 \mathrm{~g} / \mathrm{L}\left(\mathrm{NH}_{4}\right)_{2} \mathrm{HPO}_{4}, 2 \mathrm{~g} / \mathrm{L}$ glucose and without malt extract, modified after Kottke et al. 1987) was used in 50-mL Cellstar Cellreactor tubes with a $0.2-\mu \mathrm{m} \varnothing$ pore-sized filter cap (Greiner Bio-One GmbH, Germany) for P. abies and T. vaccinum co-cultivation in a climate chamber with daynight cycle of $12 \mathrm{~h}$ at $23{ }^{\circ} \mathrm{C}$ (day) and $17{ }^{\circ} \mathrm{C}$ (night) and $80 \%$ humidity. Spruce root exudates were obtained after cultivation of 1-month-old seedlings in 100-mL 20\% MMNa solution as described by Sammer et al. (2016).

Soil extracts were obtained from $100 \mathrm{mg}$ mycorrhizospheric soil taken from around $1-10 \mathrm{~cm}$ depth in triplicates under $T$. vaccinum fruiting bodies growing in association with roots of spruce (located in a coniferous forest near Jena, Germany, 50.919674, 11.525103, see Wagner et al. 2019) showing the T. vaccinum-spruce morphotype of short roots (Agerer 1987-2002). Soil extract was prepared directly after sampling $(1: 1 \mathrm{w} / \mathrm{v}$ with water, vortexed $24 \mathrm{~h}$ at room temperature in the dark), sterile filtered, and frozen at $-20{ }^{\circ} \mathrm{C}$.

For effects of phytohormones, $T$. vaccinum was cultivated in 4 replicates over 4 weeks on half concentrated MMNb plates supplemented with SA or ABA $(4 \mathrm{nM}, 4 \mu \mathrm{M}$, and $40 \mu \mathrm{M})$ in the dark. Stock solutions $(10 \mathrm{mM})$ were dissolved in ethanol. Mycelial growth area and hyphal branching were checked (see Dor et al. 2011). Since experiments were performed in biological replicates, differences in branching of the control between experiments were observed. Thus, for different phytohormone concentrations, separate controls with ethanol were considered.

\section{Phytohormone measurement}

The phytohormones abscisic acid (ABA), IAA, indole3-acetyl-alanine (IA-Ala), indol-3-acetamide (IAM), indole3-butyric acid (IBA), SA, JA, 12-oxo-phytodienoic acid (OPDA), and the derivates jasmonoyl-isoleucine (JA Ile), dicarboxy JA-Ile (COOH-JA-Ile), hydroxylated JA (OH-JA), and hydroxylated Ja Ile were measured (OH-JA-Ile; Schäfer et al. 2016) from ground mycelium, supernatant, soil extract, and root exudates. The samples were added in triplicate to 96-well BioTubes (VWR International GmbH, Germany) containing two steel balls and kept for $30 \mathrm{~min}$ at $-20{ }^{\circ} \mathrm{C}$ before incubation at $-20{ }^{\circ} \mathrm{C}$ overnight with extraction buffer (MeOH, milli-Q- $\mathrm{H}_{2} \mathrm{O}, \mathrm{HCOOH}$ 16:4:1) spiked with standards $\left[{ }^{2} \mathrm{H}_{3}\right]$-DHZ $0.25 \mathrm{ng},\left[{ }^{2} \mathrm{H}_{6}\right]-\mathrm{IP} 0.1 \mathrm{ng},\left[{ }^{2} \mathrm{H}_{5}\right]$-IAA $3 \mathrm{ng}, \mathrm{D}_{2}$-dihydro-JA and $\mathrm{D}_{5}$-JA $100 \mathrm{ng}, \mathrm{D}_{6}-\mathrm{ABA}, \mathrm{D}_{4}$-SA, and ${ }^{13} \mathrm{C}_{6}$-JA-Ile $20 \mathrm{ng}$. After vortexing and centrifugation at $1.913 \mathrm{~g}$ for $20 \mathrm{~min}$ at $4{ }^{\circ} \mathrm{C}$, the supernatant was kept at $-20^{\circ} \mathrm{C}$. A HR-X column was conditioned with $\mathrm{MeOH}$ followed by extraction buffer without standard. Flow-through was collected, the column washed with extraction buffer, and flow-through sampled again. $\mathrm{MeOH}$ was evaporated with nitrogen and $1 \mathrm{~N} \mathrm{HCOOH}$ was added to the samples, vortexed, and centrifuged. Mass spectrometry analyses were performed (Bruker EvoQ-LC-QQQ-MS, Zorbax Eclipse XDB- $\mathrm{C}_{18}$ column: $50 \times 3 \mathrm{~mm}, 1.8 \mu \mathrm{m}$, Agilent) in solvent A ( $0.05 \%$ formic acid; $0.1 \%$ acetonitrile in water) and solvent $\mathrm{B}$ (MeOH gradient: constant flow at $400 \mu \mathrm{L} / \mathrm{min}$; time/\% $\mathrm{B}, 0 / 5$, $0.5 / 5,0.6 / 50,2.5 / 100,3.5 / 100,3.55 / 5,4.5 / 5)$ with an injection volume of $1 \mu \mathrm{L}$. Multiple-reaction-monitoring mode was used (ESI positive and negative ionization mode, ion spray voltage $4500 \mathrm{eV}$, cone temperature $350{ }^{\circ} \mathrm{C}$, cone gas flow $30 \mathrm{psi}$, heated probe temperature/flow $400{ }^{\circ} \mathrm{C} / 40 \mathrm{psi}$, nebulizer gas flow $60 \mathrm{psi}$, collision gas $1.5 \mathrm{mTorr}$ ).

\section{VOC measurements}

VOCs in the headspace of 4-week-old axenic T. vaccinum cultures were sampled over $24 \mathrm{~h}$ (for geosmin $48 \mathrm{~h}$ ) via solidphase microextraction (SPME; Supelco DVB/CAR/PDMS, Bellefonte, PA, USA; see Henke et al. 2015a), followed by GC-MS analyses (Finnigan Trace GC and Trace MS detector, Thermo Fisher Scientific, Dreieich, Germany) equipped with a ZB5 column $(15 \mathrm{~m} \times 0.25 \mathrm{~mm} \times 0.25 \mu \mathrm{m})$ with $10 \mathrm{~m}$ Guardian End (Phenomenex, Aschaffenburg, Germany). Measurements were executed in electron impact (EI) mode with $70 \mathrm{eV}$ at $1.5 \mathrm{~mL} / \mathrm{min}$ helium. The GC injector (split ratio $1: 7$ ), transfer line, and ion source were set at $220^{\circ} \mathrm{C}$, $280{ }^{\circ} \mathrm{C}$, and $200{ }^{\circ} \mathrm{C}$, respectively. Spectra in the total-ioncurrent mode were taken with the programmed conditions from $40{ }^{\circ} \mathrm{C}$ followed by $10{ }^{\circ} \mathrm{C} / \mathrm{min}$ to $200{ }^{\circ} \mathrm{C}$. Spectra of the fungal volatiles geosmin, $\beta$-barbatene, and limonene were obtained using authentic standards. Standards of $( \pm)$ geosmin and limonene were obtained from Sigma-Aldrich, Germany, and barbatene isomers were kindly provided by Stefan von Reuss (Neuchatel, Switzerland). For ethylene measurements, T. vaccinum was inoculated in $2 \mathrm{~mL}$ of half concentrated MMNb in 4-mL vials and incubated over 2 weeks without shaking before supplementation with $100 \mu \mathrm{L}$ spruce root exudates or soil extract. MMNb medium with the supplements, but without the fungus, was used as control. For each treatment, three replicates were used. After 2 weeks of further incubation to achieve high VOC concentrations for the slow growing $T$. vaccinum, ethylene was measured with a photoacoustic laser spectrometer (Sensor Sense Nijwegen Netherlands; Wu et al. 2007).

\section{In silico analyses}

The genome of T. vaccinum GK6514 is available on request via JGI IMG (http://img.jgi.doe.gov/) under the submission ID59348. The genome was scanned for genes involved in phytohormone or VOC biosynthesis using BLASTN search with software sequence server (http://www.sequenceserver. com) and NCBI database (http://blast.ncbi.nlm.nih.gov). Only experimentally verified protein sequences were used 
for the search. Further online tools of JGI IMG (http://img. jgi.doe.gov/) allowed to identify potential phytohormone and volatile biosynthesis proteins based on KEGG pathways and the identification of encoded proteins of the neighboring genes in the fully sequenced genome of $T$. vaccinum.

Using sesquiterpene synthase genes in Coprinus cinerea okayama (Agger et al. 2009), a gene with geosmin biosynthesis function was suggested. Sequences were analyzed and illustrated using BioEdit. The alignment was performed in MAFFT v7 (Katoh and Toh 2008) using BLOSUM80 and E-INS-I (Katoh and Standley 2013). Using Vector NTI software, multiple sequence alignments were performed using algorithms by Notredame et al. (2000).

\section{RNA-Seq analysis}

Two different treatments were performed including $T$. vaccinum in pure MMNb medium and T. vaccinum spruce mycorrhiza in MMNa medium containing 2 g glucose/L, see also Material and methods/Cultivation of T. vaccinum and supplementary Fig. S1a. The slowly growing $T$. vaccinum needs long time to develop mature mycorrhiza. A liquid system was therefore used for the cultivation to allow for better long-term fitness of the plant and easier control of possible contamination. The samples were harvested for RNA-Seq after 8-month cultivation of $T$. vaccinum with and without spruce. Because only well-mycorrhized material should be used for the study, thin sections of the roots were produced and successful mycorrhiza formation was checked (Henke et al. 2015b, supplementary Fig. S1b, c). Predominantly fungal parts of mycorrhiza and fungal mycelia were harvested and ground with a pestle and mortar using liquid nitrogen. Total RNA was isolated (Erdmann et al. 2012) using RNeasy Plant Mini Kit (QIAGEN Hilden, Germany) with three biological replicates of cultures of each treatment. StarSEQ GmbH (Mainz, Germany) performed a check of RNA samples (Bioanalyzer, Qubit), isolated mRNA from total RNA, prepared a RNA library, performed sequencing of $2 \times 150 \mathrm{nt}$ with Illumina Next Seq 500, delivered data of FASTQ files (50 mio PE reads $(2 \times 150 \mathrm{nt}, 7.5 \mathrm{~Gb}) / \mathrm{sample})$. Further RNA-Seq data were aligned to the genomes of $T$. vaccinum and P. abies 1.0 (https://jgi.doe.gov, http://congenie.org/ blast., TopHat, FPKM/RPKM) and pairwise comparison with Cufflinks workflow was performed to show differential expression of genes (see at http://cole-trapnell-lab.github.io/ cufflinks/cuffdiff/index.html).

\section{Deuterium-labeled substrate feeding experiments for volatile biosynthesis}

Liquid cultures of $T$. vaccinum GK6514 in $\mathrm{MMNb}$ broth spiked with $3 \mathrm{mg}$ deuterated mevalonolactone per $30 \mathrm{~mL}$ culture broth, a non-spiked control, and $3 \mathrm{mg}$
1-deoxy-D-xylulose 5-phosphate (DOX, a precursor of the non-mevalonate pathway) per $30 \mathrm{~mL}$ culture broth were used to confirm the secondary metabolite pathway in the synthesis of geosmin in T. vaccinum. After 4 weeks of growth, VOCs in the headspace of the axenic T. vaccinum cultures were sampled for $48 \mathrm{~h}$ via solid-phase microextraction, as described above. Conditioning of fibers followed the manufacturer's instructions, followed by GC-MS analyses of the collected samples (Thermo Scientific MS ISQ LT and Trace 1310, Dreieich, Germany) using a ZB5 column $(30 \mathrm{~m} \times 0.25 \mathrm{~mm} \times 0.25 \mu \mathrm{m})$ with $10 \mathrm{~m}$ Guardian End (Phenomenex, Aschaffenburg, Germany). Measurements were carried out in electron impact (EI) mode with $70 \mathrm{eV}$ at $1.5 \mathrm{~mL} / \mathrm{min}$ helium. The GC injector (split ratio $1: 10$ ), transfer line, and ion source were set at $230{ }^{\circ} \mathrm{C}, 280^{\circ} \mathrm{C}$, and $250{ }^{\circ} \mathrm{C}$, respectively. Spectra in the total-ion-current mode were taken with the programmed conditions from $40{ }^{\circ} \mathrm{C}$ ( 2 min) followed by $10{ }^{\circ} \mathrm{C} / \min$ to $230{ }^{\circ} \mathrm{C}$ and $50{ }^{\circ} \mathrm{C} / \mathrm{min}$ to $300{ }^{\circ} \mathrm{C}$.

\section{qRT-PCR and target gene expression analyses}

Using 3-week-old T. vaccinum cultures, total RNA was isolated (Erdmann et al. 2012). To check the geosmin biosynthesis by the mevalonate pathway, $3 \mathrm{mg}$ mevalonolactone dissolved in $100 \mu \mathrm{L}$ sterile MMNb liquid broth was added to the culture and incubated for $6 \mathrm{~h}$. For control, the same treatment without mevalonolactone was analyzed. To check the regulation of geosmin in the communication between the fungus and its plant host, 8-week-old co-cultures of $T$. vaccinum with $P$. abies were compared with axenic $T$. vaccinum grown under the same conditions. Regulation of $T$. vaccinum geosmin while interacting with selected bacteria isolated from the T. vaccinum-P. abies mycorrhizosphere (see Wagner et al. 2019) was also tested by 3-week-old $T$. vaccinum cultures with Bacillus cereus, Bacillus zhangzhouensis, and Lysinibacillus sp. in divided Petri dishes allowing VOC exchange for $72 \mathrm{~h}$. After total RNA extraction, cDNA of all samples and replicates were synthesized using QuantiTect Reverse Transcription Kit (QIAGEN Hilden, Germany).

Gene expression changes for the candidate gene ges 1 (g5920) for geosmin production were observed using designed primers (forward: 5'CACTTCCCAAATACA GACCGTTCCC 3' and reverse 5'AAATCTTCGCTGGGT GCCCTCT3') spanning an intron (primer synthesis Eurofins Genomics, Ebersberg, Germany). For reference, genes act 1 , cis 1 , and tefl coding for actin, citrate synthetase, and translation elongation factor $(\mathrm{EF} 1 \alpha)$, respectively, were used with three technical replicates for each cDNA sample. The qPCR was carried out using Cepheid Thermocycler (Sunnyvale, USA) with SYBR Green fluorescence detection kit. Primer efficiencies were calculated using a dilution series 
of the cDNA and expression ratios normalized using the methods described by Pfaffl (2001).

\section{Results}

\section{Contribution of $T$. vaccinum to phytohormones in mycorrhizosphere soil}

T. vaccinum produced different phytohormones in liquid axenic cultures. Of those produced, IAA, IAM, SA, ABA, and JA-Ile were also found in soil extracts (Fig. 1). Spruce root exudates had a less diverse phytohormone pattern, including only IAA, IAM, and SA. However, the concentration of IAA and IAM was much higher in exudates (47.72 IAM area/standard; 136.54 IAA area/standard) than in soil (0.11 IAM area/standard; 0.16 IAA area/standard) or in $T$. vaccinum axenic cultures (0.31 IAM area/standard; 1.6 IAA area/standard). SA was found in all three environments, with $0.5 \mathrm{ng} / \mathrm{mg}$ around $T$. vaccinum mycelium, $0.9 \mathrm{ng} / \mathrm{mg}$ in the soil extract, and $1.6 \mathrm{ng} / \mathrm{mg}$ exuded by spruce roots (supplementary Fig. S2). In contrast, ABA was not excreted by the plant, but found in $T$. vaccinum cultures $(0.1 \mathrm{ng} / \mathrm{mg})$ and in mycorrhizosphere soil $(0.01 \mathrm{ng} / \mathrm{mg}$, supplementary Fig. S2). Like ABA, JA-Ile was measured in T. vaccinum cultures $(0.004 \mathrm{ng} / \mathrm{mg})$ and soil extract $(0.009 \mathrm{ng} / \mathrm{mg})$, albeit at very low concentrations, but was absent in root exudates.

\section{Effect of phytohormones on $T$. vaccinum}

Since phytohormones are major contributors to signaling compounds in ectomycorrhizal soil, their effect on both partners needs to be considered. While plant response to external phytohormones is well known, the effects on the fungal partner are less well described. Thus, prominent phytohormones found in the root exudates of $P$. abies (spruce) and soil extract were used to test for effects on radial growth and hyphal branching of $T$. vaccinum. Three concentrations of each phytohormone were tested. Cultures were supplemented in a concentration gradient reflecting the naturally occurring phytohormone levels found in this study. For the three different concentrations of SA, a corresponding increase in radial growth of $T$. vaccinum was observed (Fig. 2). Hyphal branching (both primary and secondary branching) was significantly reduced in all tested concentrations of SA. ABA inferred a considerable increase in the radial growth of $T$. vaccinum at $40 \mu \mathrm{M}$ concentration and caused hyperbranching in the fungus (see Fig. 2). However, $40 \mu \mathrm{M}$ is exceeding widely physiological concentrations.

\section{VOC production in T. vaccinum}

To test for potential signaling molecules, also volatile compounds were considered. T. vaccinum released different VOCs (Fig. 3; supplementary Table S1). The highest peak intensities belonged to the typical fungal VOCs oct-1-en3-ol (13.3\%) and 3-octanone (7.5\%), known to correspond to the mushroom odor. Very low peak intensity indicated the presence of pentyl propanoate $(0.4 \%)$ and limonene $(0.5 \%)$ usually considered a plant VOC in cultures of the fungus without tree. Moreover, T. vaccinum produced the metabolite $\beta$-barbatene known from plants $(4.4 \%)$ and the odor typical for streptomycetes, geosmin (2.0\%, supplementary Fig. S3).

Ethylene concentrations in the headspace amounted to $5.7 \mathrm{~nL} / \mathrm{mg}$ T. vaccinum biomass in axenic culture. The production was not significantly affected by supplementation with spruce exudates $(4.1 \mathrm{ng} / \mathrm{mg})$. However, significantly less ethylene was found in the presence of rhizospheric soil ( $0.4 \mathrm{ng} / \mathrm{mg})$, likely due to microbial metabolism or signaling.

\section{In silico prediction of the potential biosynthesis genes}

Since SA, JA, ET, geosmin, and limonene were produced by T. vaccinum, potential biosynthetic pathways were identified from the genome sequence. Here, only protein sequences of experimentally verified function from plants, fungi, and bacteria were considered which are associated with the corresponding function in KEGG pathways (Fig. 4). The comparison of SA and JA pathways in $T$. vaccinum with other organisms using KEGG maps and Blast analyses showed identity to plant pathways. The obtained SA pathway is
Fig. 1 Qualitative analyses of phytohormones in spruce root exudates, soil extract from mycorrhizospheric sampling site, and $T$. vaccinum liquid cultures; light gray: no detection, black: production verified, dark gray: only found in supernatant not mycelium

\begin{tabular}{|l|l|l|l|}
\hline & spruce root exudate & soil extract & T. vaccinum mycelium \\
\hline abscisic acid & & & \\
\hline indole-3-acetid acid & & & \\
\hline indole-3-acetyl-alanine & & & \\
\hline indole-3-acetamide & & & \\
\hline indole-3-butyric acid & & & \\
\hline jasmonates & & & \\
\hline jasmonoyl-isoleucine & & & \\
\hline hydroxylated jasmonates & & & \\
\hline dicarboxy jasmonoyl-isoleucine & & & \\
\hline 12-oxo-phytodienoic acid & & & \\
\hline salicylic acid & & & \\
\hline
\end{tabular}


Fig. 2 Effects of feeding of salicylic acid (SA) or abscisic acid (ABA) on growth (a) and branching (b) of $T$. vaccinum. Cultures were supplemented in a concentration gradient reflecting the naturally occurring phytohormone levels; 1 : primary branch, 2: secondary branch, error bars indicate standard deviations, significant differences: $* p<0.05$
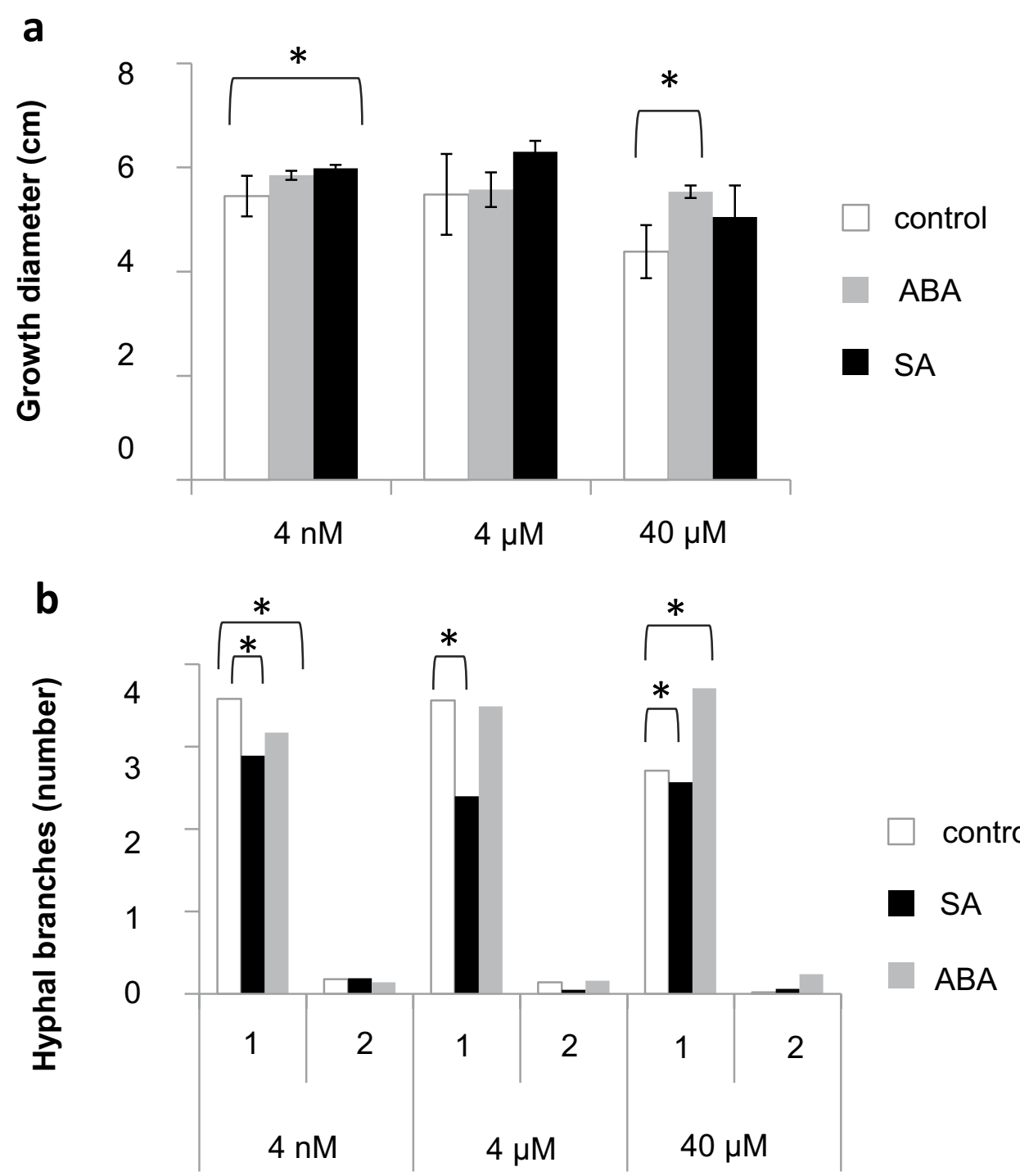

linked to the isochorismate pathway in plants (Dempsey et al. 2011), but a gene encoding an isochorismate pyruvate lyase, which is discussed in plant biosynthesis pathways to catalyze the last step, was lacking from the fungal genome. A putative replacement was not identified.

Also, for JA biosynthesis pathway (Fig. 4), only one gene was missing. A jasmonate-amido synthetase catalyzing the formation of the biologically active jasmonoyl-isoleucine, known from A. thaliana with JAR1 (Guranowski et al. 2007), could not be identified from T. vaccinum. This corresponds to other fungi, where this gene is not present. However, some ectomycorrhizal basidiomycetes like Boletus edulis Bed1, Suillus edulis (protein ID 2761262324), and Laccaria bicolor (protein ID 2762831280) are available with this exact annotation lacking homologs in $T$. vaccinum.

ET biosynthesis enzymes of two microbial pathways were found in T. vaccinum; the 4-(methylsulfanyl)-2-oxobutanoate (KMBA) pathway starting with methionine is similar to that 

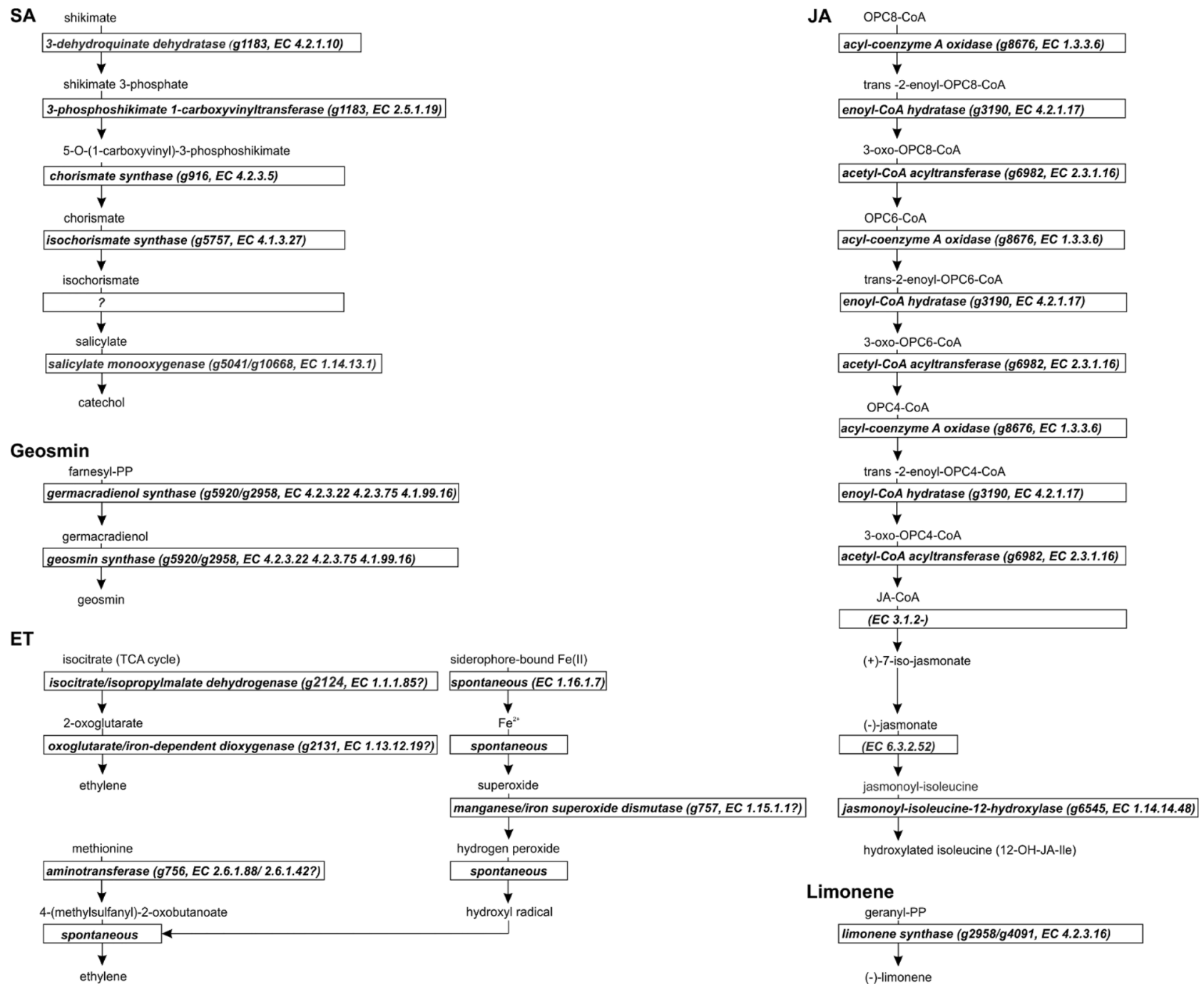

Fig. 4 Potential phytohormone and volatile biosynthesis pathways, based on KEGG pathways of the fully sequenced genome of $T$. vaccinum, are presented with EC numbers and gene IDs. For salicylic acid (SA), a 3-dehydroquinate dehydratase (g1183), a 3-phosphoshikimate 1-carboxyvinyltransferase (g1183), a chorismate synthase (g916), an isochorismate synthase (g5757), and salicylate monooxygenases (e.g., g5041, g10668) were identified, but no isochorismate pyruvate lyase, which is thought to catalyze the last step to salicylic acid, was found. For jasmonic acid (JA), an acyl-coenzyme A oxidase (g8676), an enoyl-CoA hydratase (g3190), an acetyl-CoA acyltransferase (g6982), and Cytochrome P450 family 94 functioning as jasmonoylisoleucine-12-hydroxylase (g6545) were identified, but no enzymes catalyzing steps from JA-CoA to jasmonoyl-isoleucine, like jasmonoyl-L-amino acid synthetase, which is catalyzing the biological

present in plants. The second pathway, the EFE pathway (Fig. 4), is very different from that present in plants (Groen and Whiteman 2014). No hits were identified for ABA biosynthesis genes using the available plant homologs.

We additionally checked for phytohormone synthesis islands in analyzing the neighboring genes of the identified phytohormone synthesis clusters (see supplementary active jasmonoyl-isoleucine from jasmonate in Arabidopsis thaliana. For geosmin, g5920 and g2958 were identified to be germacradienol/ geosmin synthases. For ethylene (ET) 4-(methylsulfanyl)-2-oxobutanoate (KMBA) pathway, methionine is catalyzed by an aminotransferase (g756) to 4-(methylsulfanyl)-2-oxobutanoate. A manganese/ iron superoxide dismutase (g757) is catalyzing a precursor reaction resulting in a hydroxyl radical for final spontaneous reaction from 4-(methylsulfanyl)-2-oxobutanoate to ethylene. In ET EFE pathway, an isocitrate/isopropylmalate dehydrogenase (g2124) catalyzes the reaction from isocitrate of the TCA cycle to 2-oxoglutarate which is formed by an oxoglutarate/iron-dependent dioxygenase (g2131) to ethylene. For limonene, g2958 and g4091 forming limonene from geranyl diphosphate were identified

Table S2, Figs. S4-S8), but could not verify linkage of the biosynthesis clusters. This corresponds also to the known pathway for synthesis of IAA (Krause et al. 2015; Henke et al. 2016). However, we found clusters for the two ET synthesis pathways. For the 4-(methylsulfanyl)-2-oxobutanoate (KMBA) pathway, next to an aminotransferase (g756), a manganese/iron superoxide dismutase (g757) is localized 
catalyzing a precursor reaction to obtain a hydroxyl radical for the final, spontaneous reaction from 4-(methylsulfanyl)2-oxobutanoate to ethylene (supplementary Fig. S7). Also, for the isocitrate/isopropylmalate dehydrogenase (g2124), a linked gene for the enzyme catalyzing the reaction from isocitrate of the TCA cycle to 2-oxoglutarate was found (g2131). The latter is responsible for ethylene release by an oxoglutarate/iron-dependent dioxygenase. Next to that gene, an S-adenosyl-L-methionine-(SAM)-dependent methyltransferase (g2130) is localized, which is involved in plant ethylene production (Moffatt and Weretilnyk 2001). However, both pathways are not entirely assembled in a cluster that would suggest heterologous gene transfer for acquisition of ethylene biosynthesis.

As for the identified terpenoids, geosmin biosynthesis genes were detected with g2958 on contig 3429, a germacradienol/geosmin synthase, and a sesquiterpene synthase on contig 11698 (Fig. 4). This gene showed only low similarity to bacterial geosmin synthases, but was highly similar to Cop3 of Coprinus cinereus (Agger et al. 2009).

Possible limonene biosynthesis genes were identified with again g2958, the probable geosmin biosynthesis gene, and branching from that route g4091 coding for a limonene synthase responsible for the one-step cyclization of geranyl diphosphate into limonene (Fig. 4; see supplementary Table S2 and Fig. S8). Both are similar to fungal terpene synthases (see supplementary Table S3), g2958 to a protein of the ascomycete Hypoxylon sp., Hyp3, encoding a 1,8 cineole synthase producing $90 \%$ cineole and $10 \%$ limonene. The gene g4091 showed similarity to an aristolochene synthase from Aspergillus terreus, evolutionarily similar with cineole synthases (Shaw et al. 2015). Genes coding for enzymes associated with $\beta$-barbatene biosynthesis were not detected based on plant homologs.

\section{Unraveling the biosynthesis of the VOC geosmin}

The production of sesquiterpenes could be predicted to follow the mevalonate pathway. Therefore, $T$. vaccinum was grown in the presence of $3 \mathrm{mg}{ }^{2} \mathrm{H}_{2}$-mevalonolactone for 4 weeks. Deuterium-labeled geosmin was seen with 15 to $29 \%$ label incorporation confirming the biosynthesis route (Fig. 5). To check for a contribution from the DOX pathway, $T$. vaccinum cultures spiked with $3 \mathrm{mg}^{2} \mathrm{H}_{2}$-DOX were

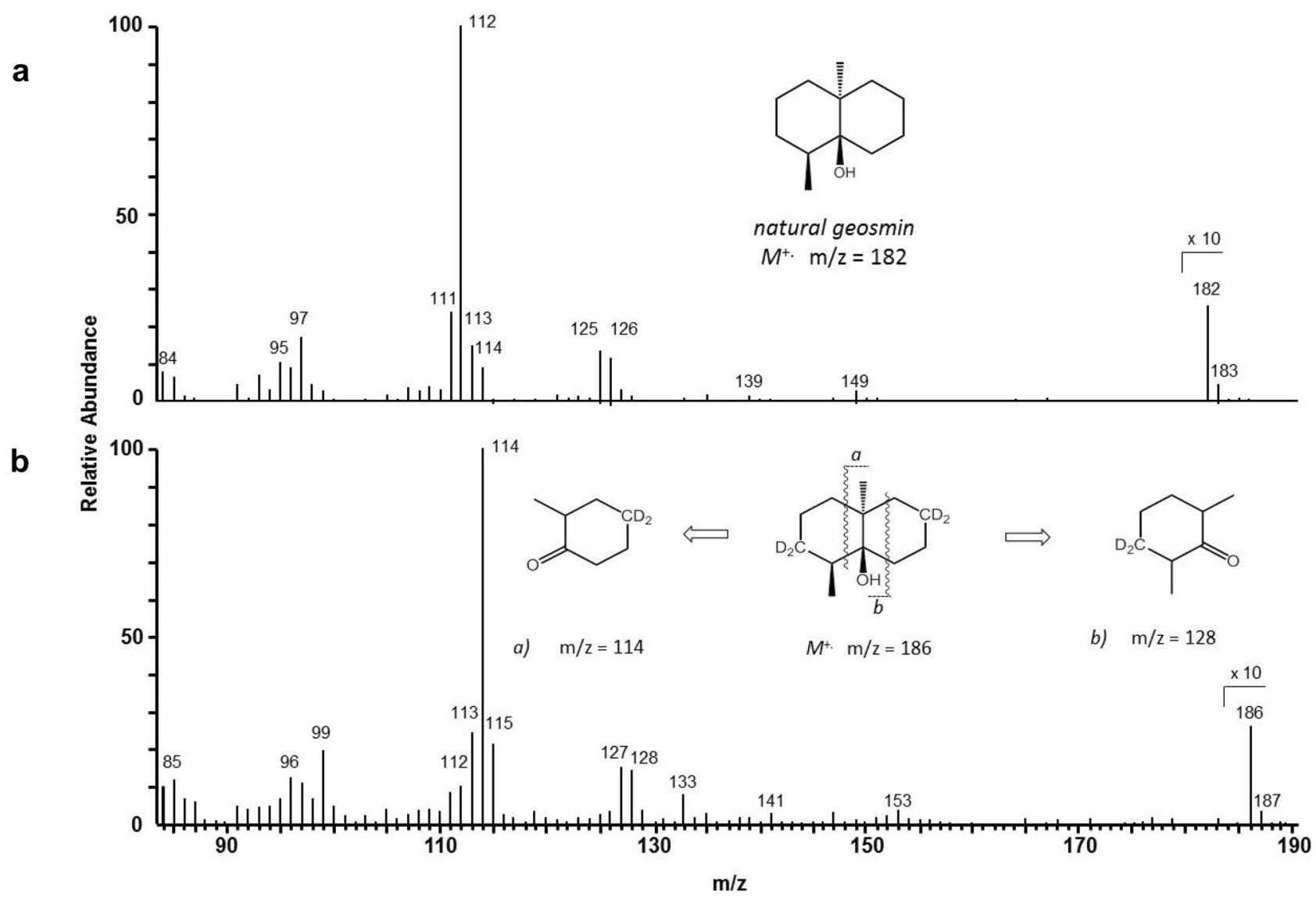

Fig. 5 Mass spectra of natural geosmin $(\mathbf{a}, \mathbf{b})\left[{ }^{2} \mathrm{H}_{4}\right]$-geosmin at $\mathrm{m} / \mathrm{z}=186$ along with the two fragments at $\mathrm{m} / \mathrm{z}=114$ and $\mathrm{m} / \mathrm{z}=128$ indicating the presence of two deuterium atoms in each of the two fragments 
analyzed. No incorporation of ${ }^{2} \mathrm{H}_{2}$-DOX into geosmin was seen, which implies that geosmin biosynthesis in $T$. vaccinum exclusively proceeds via the classical mevalonate pathway and rules any contribution from bacteria (or endophytes) using the MEP-pathway. According to the high degree of deuterium labeling in $\left[{ }^{2} \mathrm{H}_{4}\right]$-geosmin (approx. $25 \%$ ), the added $\left[{ }^{2} \mathrm{H}_{2}\right]$-mevalonolactone was efficiently converted into labeled farnesyl diphosphate $\left[{ }^{2} \mathrm{H}_{6}\right]$-FDP. The farnesyl diphosphate then was converted to the cyclic geosmin along a known sequence (Jiang and Cane 2008; Jiang et al. 2006, 2007; Spiteller et al. 2002), which involves a loss of a $\mathrm{C}_{3}$ segment with two deuterium atoms.

The mass spectrum of natural geosmin displays two even numbered fragments at $\mathrm{m} / \mathrm{z}=112$ and 126 of high diagnostic value. Together with the molecular ion at $\mathrm{m} / \mathrm{z}=182$, they allow the localization of the isotopes within the bicyclic skeleton of geosmin (Spiteller et al. 2002). As shown in Fig. 5, the fragment of $\mathrm{m} / \mathrm{z}=112$ was shifted to $\mathrm{m} / \mathrm{z}=114$, while at the same time, the second fragment at $\mathrm{m} / \mathrm{z}=126$ was shifted to $\mathrm{m} / \mathrm{z}=128$. The molecular ion raised from $\mathrm{m} / \mathrm{z}=182$ to $\mathrm{m} / \mathrm{z}=186$, indicating that in total, four deuterium atoms were present at the assigned positions in the geosmin molecule.

\section{Expression and regulation of the putative biosynthesis genes}

By RNA-Seq analyses, pure fungal mycelium was compared with mycorrhizae to verify expression and regulation of genes involved in potential phytohormone or volatile biosynthesis pathways in mature mycorrhizae (see Table 1, compare supplementary B).

As for the phytohormones, tryptophan aminotransferase taml for IAA biosynthesis as well as a gene encoding auxin efflux carrier transmembrane protein showed up-regulation in mycorrhiza. The aldehyde dehydrogenases ald2-ald 4 were

Table 1 Expression changes of T. vaccinum genes encoding proteins potentially involved in phytohormone and volatile biosynthesis based on RNA-Seq analyses with treatment pure fungal culture versus mycorrhiza

\begin{tabular}{|c|c|c|c|}
\hline Gene ID & Function in biosynthesis pathway & $\begin{array}{l}\log 2 \text { fold changes in RNA- } \\
\text { Seq }\end{array}$ & Significance \\
\hline $\mathrm{g} 2124$ & ET: isocitrate/isopropylmalate dehydrogenase & 0.0555816 & No \\
\hline $\mathrm{g} 2131$ & ET: oxoglutarate/iron-dependent dioxygenase & 0.355883 & No \\
\hline g756 & ET: branched-chain amino acid aminotransferase & -1.3683 & Yes \\
\hline g757 & ET: Manganese/iron superoxide dismutase & 0.449477 & No \\
\hline g1183 & SA: 3-dehydroquinate dehydratase & -0.378181 & No \\
\hline g916 & SA: chorismate synthase & 0.0602133 & No \\
\hline g5757 & SA: isochorismate synthase & -0.204483 & No \\
\hline g5041 & SA: salicylate monooxygenase & 1.87578 & Yes \\
\hline g10668 & SA: salicylate monooxygenase & -0.0884607 & No \\
\hline g8676 & JA: acyl-coenzyme A oxidase & 0.371859 & No \\
\hline g3190 & JA: enoyl-CoA hydratase & -0.664495 & No \\
\hline g6982 & JA: acetyl-CoA acyltransferase & -0.104792 & No \\
\hline g6545 & JA: jasmonoyl-isoleucine-12-hydroxylase & -0.712133 & No \\
\hline g5920 & Geosmin: germacradienol/ geosmin synthases & -0.0812449 & No \\
\hline g2958 & Geosmin, Limonene: germacradienol/geosmin/ limonene synthases & 1.23004 & No \\
\hline g4091 & Limonene: Geranyl diphosphate lyase (Limonene forming) & 2.42992 & No \\
\hline $\mathrm{g} 2731$ & IAA: tryptophan aminotransferase Tam1 & 1.11115 & Yes \\
\hline $\mathrm{g} 4322$ & IAA: indole-3-pyruvic acid (IPA) decarboxylase Ipd1 & -0.810077 & No \\
\hline g7538 & IAA: aldehyde dehydrogenase $(\mathrm{NAD}(\mathrm{P})+)$ Ald1 & -1.41141 & No \\
\hline g5206 & IAA: aldehyde dehydrogenase $(\mathrm{NAD}(\mathrm{P})+)$ Ald2 & -1.91556 & Yes \\
\hline g6636 & IAA: aldehyde dehydrogenase $(\mathrm{NAD}(\mathrm{P})+)$ Ald3 & -1.59273 & Yes \\
\hline $\mathrm{g} 2541$ & IAA: aldehyde dehydrogenase $(\mathrm{NAD}(\mathrm{P})+)$ Ald4 & -1.59273 & Yes \\
\hline g6551 & IAA: aldehyde dehydrogenase $(\mathrm{NAD}(\mathrm{P})+)$ Ald5 & 0.389237 & No \\
\hline g34 & IAA: aldehyde dehydrogenase $(\mathrm{NAD}(\mathrm{P})+)$ Ald6 & -0.130813 & No \\
\hline g5201 & IAA: aldehyde dehydrogenase $(\mathrm{NAD}(\mathrm{P})+)$ Ald7 & -0.359637 & No \\
\hline g2766 & IAA: Prephenate dehydrogenase (NADP+) TyrA & -0.67403 & No \\
\hline g7957 & IAA: auxin efflux carrier transmembrane protein & 3.27473 & Yes \\
\hline
\end{tabular}

The expression values of three biological replicates of both treatments were used for $\log 2$ fold change calculation. Significant data show a $p$ value $\geq 0.005$ 
downregulated, indicating that those genes are not specifically involved in IAA synthesis. In the SA pathway, up-regulation of the SA degrading enzyme salicylate monooxygenase was seen in mycorrhiza, indicative for SA being rather in excess during symbiosis. For JA, no significantly changed expression was observed. The ET (KMBA) pathway seems to be down-regulated during mycorrhization, as the aminotransferase showed significant repression.

For the biosynthesis of the VOCs geosmin and limonene, no significant regulatory pattern was found. This prompted us to further investigate the geosmin biosynthesis genes for expression signals by qRT-PCR. The identified gene ges 1 (g5920) shows typical sequence motifs of sesquiterpene synthases, high sequence identity with fungal sesquiterpene synthases of $C$. cinerea okayama, and lower similarity with bacterial geosmin synthases (Fig. 6). Thus, the biosynthesis pathway was tested using potential precursors. The mevalonate pathway for secondary metabolism was tested feeding mevalonolactone to the fungal culture. A more than two-fold (2.37, Fig. 7) increase in ges 1 expression suggested involvement of this gene in the biosynthesis of geosmin. Expression of ges 1 in 8-week-old interaction with the plant host showed a 7.41-fold increase compared with axenic culture of the fungus (see Fig. 7), which further strengthened the notion of a role of geosmin in the communication between plant and fungus while mycorrhiza is still young. In validation of the RNAseq data, qRT-PCR was performed. As often observed, the amount of fold change was different as compared with g5920.t1 T. vaccinum XP_001832925 Cop3 C. cinerea XP_001832573 Cop1 C. cinerea Q9र्ष839.3 S. coelicolor

g5920.t1 T. vaccinum XP_001832925 Cop3 C. cinerea $\mathrm{XP}-001832573$ Cop1 C. cinerea Q9X839.3 S. coelicolor

g5920.t1 T. vaccinum XP 001832925 Cop3 C. cinerea XP 001832573 Cop1 C. cinerea Q9र $\overline{8} 39.3$ S. coelicolor

g5920.t1 T. vaccinum XP 001832925 Cop3 C. cinerea XP_001832573 Cop1 C. cinerea Q9X839.3 S. coelicolor

g5920.t1 T. vaccinum XP_001832925 Cop3 C. cinerea XP_001832573 Cop1 C. cinerea Q9 $\overline{\mathrm{X}} 839.3 \mathrm{~s}$. coelicolor

g5920.t1 T. vaccinum XP_001832925 Cop3 C. cinerea XP_001832573 Cop1 C. cinerea Q9X̄839.3 S. coelicolor

g5920.t1 T. vaccinum XP 001832925 Cop3 C. cinerea XP 001832573 Cop1 C. cinerea Q9र839.3 s. coelicolor

g5920.t1 T. vaccinum XP 001832925 Cop3 C. cinerea XP_001832573 Cop1 C. cinerea Q9X839.3 S. coelicolor

g5920.t1 T. vaccinum XP_001832925 Cop3 C. cinerea XP_001832573 Cop1 C. cinerea Q9X̄839.3 S. coelicolor

g5920.t1 T. vaccinum XP_001832925 Cop3 C. cinerea XP 001832573 Cop1 C. cinerea o9x $839.3 \mathrm{~s}$. coelicolor

g5920.t1 T. vaccinum XP 001832925 Cop3 C. cinerea XP 001832573 Copl C. cinerea Q9X839.3 S. coelicolor
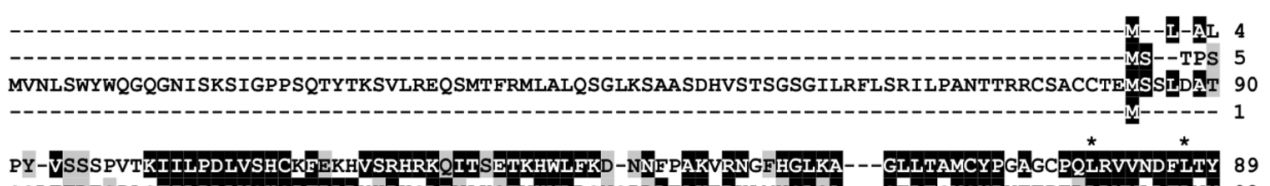
SSLTTDESPASF ILPDLVSHCPFPLRYHPKGDEVAKOTVHWLDSNCPDLTAKERKAMYGLOA--- GELTGYCYPYTTPERLRVVADFLNY 92 IHPVLNFEDKKIVLPDLVSHCNEKLRVSRHRKRITGETKRWLFKG-DNLVGPARNKYHGLKA---GLLTAMTYPDAAYPOLRLCNDFLTY 176 ---TQQPEQLPHF--YLPHPARLNPHLDEARAHSTTWAREM-GMLEGSGVWESDLEAHDYGLLCAYTHPDCDGPALSLITDWYVW 81 $\star \star \star \star t+\hbar$
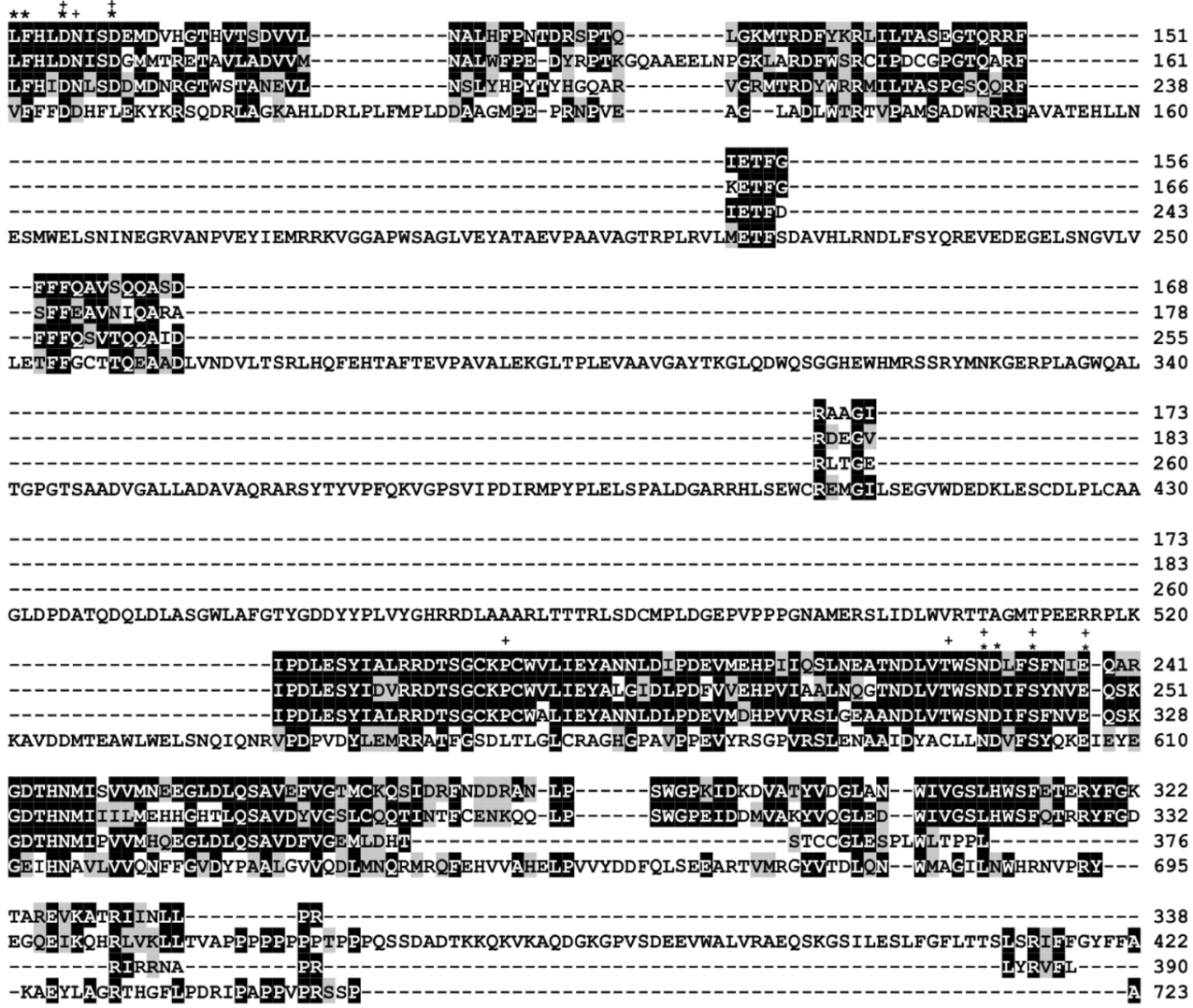

-RR 340

YSH 425

--- 390

LTH 726
Fig. 6 Multiple sequence alignment of the conceptually translated Ges1, putatively involved in geosmin biosynthesis, with fungal sesquiterpene synthases Cop1 and Cop3 from $C$. cinerea okayama and
Cyc2, a bacterial germacradienol/geosmin synthase from Streptomyces coelicolor; ${ }^{*}$, substrate binding pocket; + , substrate- $\mathrm{Mg}^{2+}$ binding site 
Fig. 7 Expression analyses of ges 1 by qRT-PCR. a Mevalonolactone was added as a precursor in the classical mevalonate pathway at $3 \mathrm{mg}^{2} \mathrm{H}_{2}$-mevalonolactone in axenic culture medium to examine geosmin biosynthesis, b young mycorrhizal interaction with spruce, $\mathbf{c}$ mature mycorrhizal interaction with spruce and validation of RNA seq data, and $\mathbf{d}$ interaction of mycelium of $T$. vaccinum with selected bacteria from the mycorrhizosphere were tested

\section{a geosmin biosynthesis}

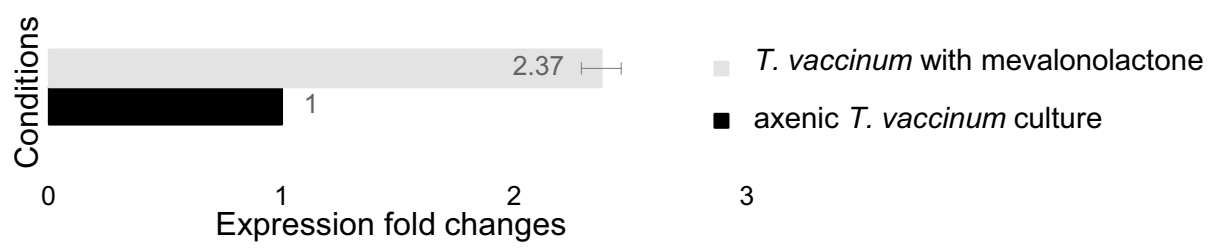

b young plant-fungal interaction

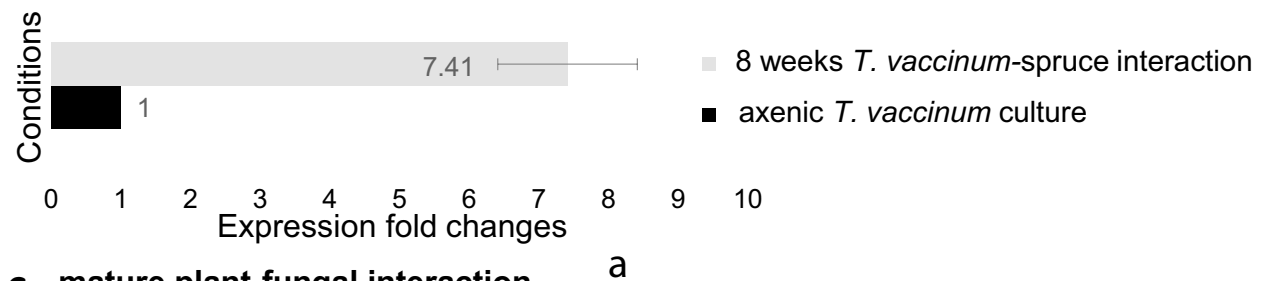

C mature plant-fungal interaction

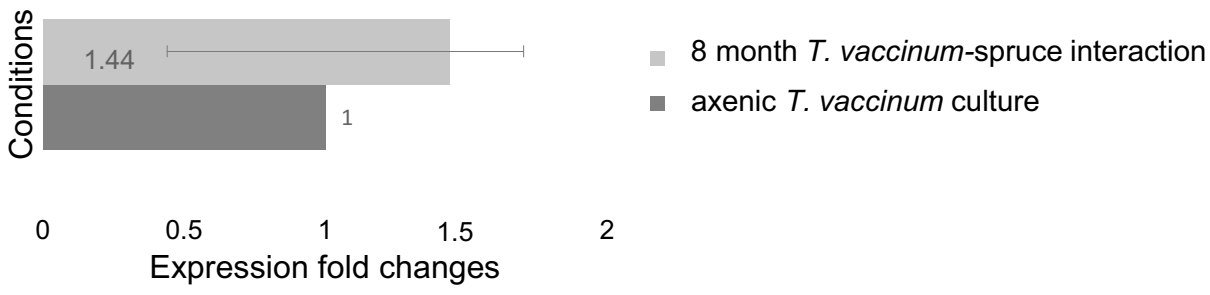

d interaction with bacteria

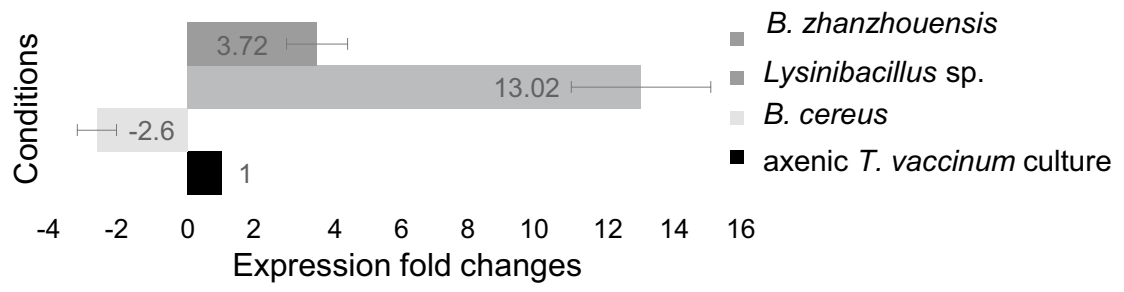

RNA-Seq, but no regulation was seen (1.44-fold increase compared with axenic culture of the fungus in an 8-monthold plant-fungus interaction). A potential impact of ectomycorrhizosphere bacteria was tested by looking at ges 1 expression in interactions of fungal mycelium with volatiles of selected mycorrhizosphere bacteria. Indeed, the interactions with B. zhangzhouensis or Lysinibacillus sp. isolated from the ectomycorrhizosphere soil showed a 3.72- and 13.02fold up-regulation, while interaction with $B$. cereus led to a 2.60-fold down-regulation (see Fig. 7). Thus, fine-tuning of VOC production in association with the co-occurring microbiome of a mycorrhiza could be verified.

\section{Discussion}

Here, we analyzed the potential of the ectomycorrhizal fungus T. vaccinum to produce phytohormones and VOCs. We detected and quantified phytohormones excreted by the roots of the host tree P. abies, by axenic fungal cultures, and those present in the mycorrhizospheric soil. The VOC profile of axenically grown $T$. vaccinum mainly comprised the typical fungal VOCs, oct-1-en-3-ol and 3-octenone (Bäck et al. 2010; Fäldt et al. 1999; Müller et al. 2013). These compounds are known to attract insects and induce plant defense, which may be inferred from Kishimoto et al. (2007), where A. thaliana defense genes were induced by low concentrations of oct-1-en-3-ol. An induced plant resistance is also supported by the finding that the rate of plant pathogen attack on spruce was reduced in mycorrhizal spruce-T. vaccinum co-cultures (Wagner et al. 2019).

The identification of geosmin as a VOC produced by $T$. vaccinum shows that also soil basidiomycetes may contribute to the earthy smell. Geosmin, in addition to enhancing sporulation (Bentley and Meganathan 1981) and spore germination in arbuscular endomycorrhizal fungi (CarpenterBoggs et al. 1995), thus might play a role also in ectomycorrhiza formation. Even if no direct effect on T. vaccinum 
was seen, promoting sporulation or germination of plant growth promoting bacteria and fungi in the spruce mycorrhizosphere might benefit the ectomycorrhiza formation. A route for the biosynthesis of the compound therefore was of interest. As no basidiomycetes had been reported to produce geosmin, the geosmin biosynthetic pathway was elucidated. T. vaccinum uses the classical mevalonate pathway. The alternative pathway known from many bacteria, plants, and apicomplexan protozoa, the 2-C-methyl-D-erythritol 4-phosphate/1-deoxy-D-xylulose 5-phosphate (MEP/DOXP) pathway (Spiteller et al. 2002) present in, e.g., Streptomyces sp., was not used by the basidiomycete. The only other reported potential biosynthesis gene in fungal geosmin production (gpel) had been found with the ascomycete mold Penicillium expansum (Siddique et al. 2012). The geosmin biosynthetic gene in $T$. vaccinum was identified to be different from gpe1. A Termitomyces sp. germacradienol/germacrene D synthase-like gene was identified in the T. vaccinum genome instead. It is noteworthy, however, that the gene is dissimilar to the germacradienol/geosmin synthase reported from actinomycetes (Jiang et al. 2007), but clusters with Coprinus cinereus and Schizophyllum commune sesquiterpene synthases (Cop1 and Tps2, respectively; Fig. 8). Using transcript analyses, an increase in expression in the presence of the precursors, as well as in young interaction with the host plant, was shown. Specific regulation of $T$. vaccinum ges 1 was seen during interaction with co-occurring bacteria showing mycorrhiza-helper abilities (Wagner et al. 2019). Since up- versus down-regulation was species-dependent, no correlation with mycorrhiza-helper abilities was visible. However, the down-regulation of gesl observed in B. cereus might instead be linked to its increase in pigment production (Wagner et al. 2019).

Other VOCs produced by T. vaccinum included the monoterpene limonene and the sesquiterpene $\beta$-barbatene, both not usually considered typical for fungal volatiles. However, both of these classical plant metabolites were found also in fruiting bodies of the brown rot fungus Fomitopsis pinicola (Fäldt et al. 1999), while limonene typically is found in Picea abies needles (Persson et al. 1996). While

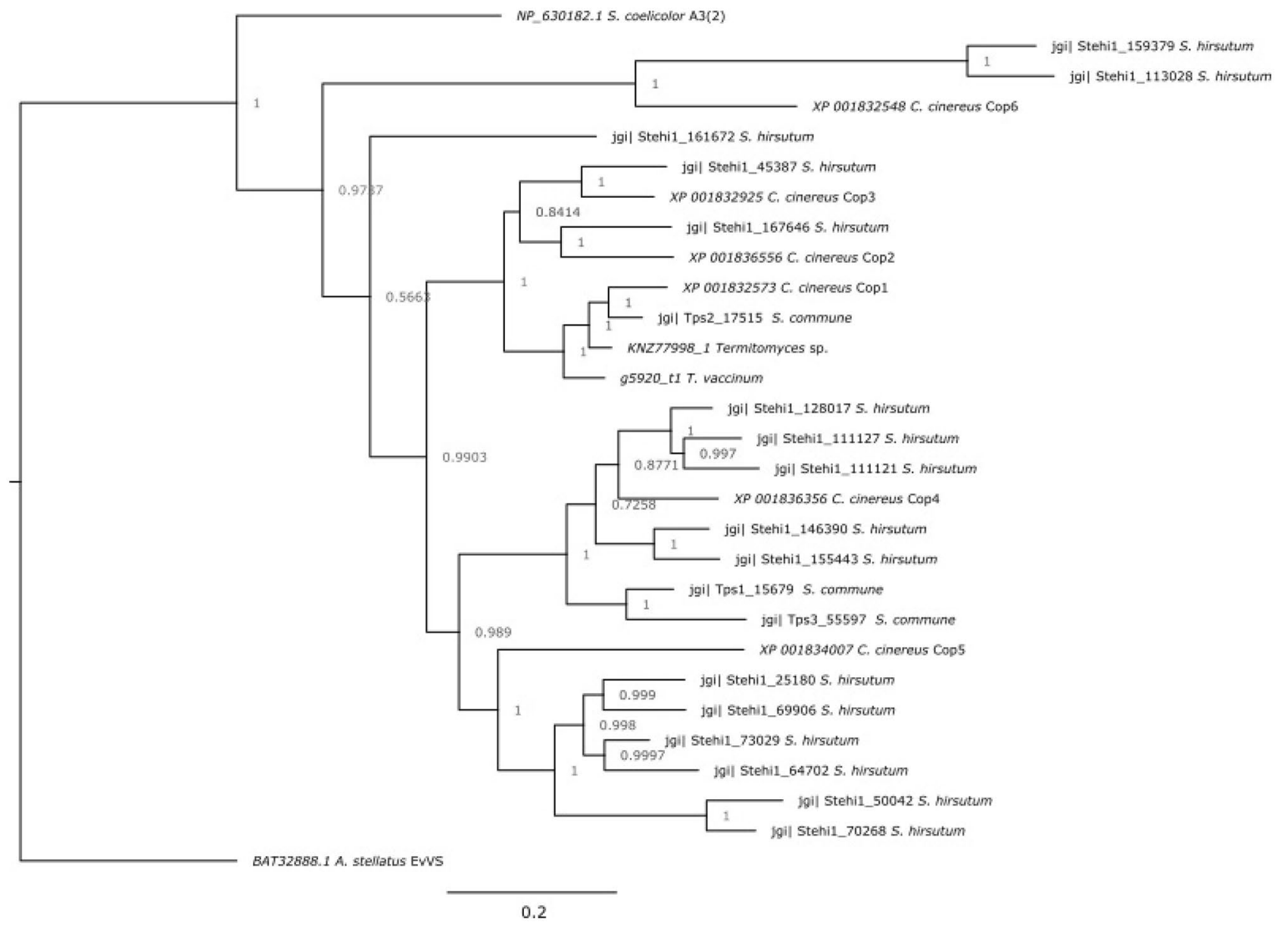

Fig. 8 Phylogenetic tree showing clusters of different sesquiterpene synthases in basidiomycetes including g5290 from T. vaccinum clearly separated from the germacradienol/geosmin synthase of Strep- tomyces coelicolor. GenBank accession numbers and JGI IDs are given with the organism names 
VOC profiles of T. vaccinum and other ectomycorrhizal fungi, like Paxillus involutus or Laccaria bicolor, differ strikingly, a similarity to $F$. pinicola VOC pattern might suggest host range specificity as an evolutionary factor for VOC patterns. This seems to be the case irrespective of symbiotic versus pathogenic life styles (Müller et al. 2013), since $F$. pinicola has been shown to be most commonly found as conifer pathogen (and in very rare cases on birches). Two possible genes involved in limonene synthesis were identified in T. vaccinum. The terpenoid synthase g2958 showed similarity to proteins in $F$. pinicola and $P$. involutus, while g4091 shows similarity with two genes in $F$. pinicola and much less to $P$. involutus (supplementary Table S3). Probably due to limited available information on monoterpene synthases in fungi (Quin et al. 2014), KEGG analyses of genes in the monoterpenoid biosynthesis pathway did not yield a hit, even though all basidiomycete genomes available were screened (including, $F$. pinicola, $P$. involutus, and L. bicolor). Therefore, manual BLAST analysis of potential limonene synthase proteins was used to identify the genes as described above. Limonene displays antimicrobial activities especially against fungi (Duetz et al. 2003). In spruce roots, the composition of the monoterpenes changed during Heterobasidion annosum attack and increased in limonene concentration (Rieger 1995). The same pattern is seen during mycorrhization with $T$. vaccinum, where limonene is the major VOC compound of the spruce profile (Henke et al. 2015a). T. vaccinum is also sensitive to limonene, but only at high, non-natural concentrations (Schlunk et al. 2015). Since $\beta$-barbatene also shows antimicrobial activity, we assume that both are involved in plant defense of P. abies (Bukvicki et al. 2013). The fungal production thus could be connected to the protection against pathogens seen with mycorrhiza (Wagner et al. 2019).

Other typical plant metabolites produced by $T$. vaccinum are phytohormones. IAA and its intermediate IAM were detected in T. vaccinum rhizospheric soil and axenic cultures in addition to the expected presence in spruce root exudates. IAA and its precursors had already been shown to increase branching in $T$. vaccinum which is a pre-requisite to produce the hyphal mantle around the plant root (Krause et al. 2015). Fungal cultures compared with mycorrhiza revealed no clear up-regulation of the genes involved in IAA biosynthesis. Some aldehyde dehydrogenases are down-regulated, which might either be indicative of no involvement of these specific dehydrogenase genes in IAA synthesis, or it may be caused by the mature mycorrhiza stage used in this study. It has been proposed that at later stages, lower IAA levels than during initiation with massive re-structuring are necessary. Thus, IAA is involved in the formation of both mantle and Hartig' net formation in early mycorrhiza (Henke et al. 2016). Nearly $75 \%$ of isolated fungi and bacteria from mycorrhizospheric soil samples were able to produce IAA
(Wagner et al. 2019) and thus to stimulate plant growth (Davies 2010; Gea et al. 1994) providing more accessible short roots for mycorrhiza formation (Wagner et al., 2019).

An involvement of $T$. vaccinum in inducing plant defense is indicated by the production of JA derivates. The conjugate JA-Ile detected in T. vaccinum cultures and in the soil samples is known to be produced by plants after wounding (Gális et al. 2009) and thus may reinforce pest resilience in mycorrhized plants. Since exogenous application of methyl jasmonate to the stem of $P$. abies activated plant defense and reduced disease symptoms caused by Ceratocystis polonica (Krokene et al. 2008), it also may induce systemic pathogen resistance. Many fungi like Coprinus species, Mycena galericulata, or Trametes versicolor have been shown to produce JA (Miersch et al. 1993). The predicted biosynthesis genes in $T$. vaccinum show sequence similarity to a protein of Aspergillus niger with strong similarities to the oxophytodienoic acid reductase from plants, which is a key enzyme in JA biosynthesis (Taki et al. 2005).

SA is an effective substance in Norway spruce defense, e.g., against the pathogen Heterobasidion parviporum that causes stem and butt rot (Arnerup et al. 2013). For mycorrhiza, it has long been proposed that plant defense needs to be reduced to allow for colonization. Accordingly, downregulation of gene expression in SA and ET biosynthesis was shown here. As an effect on the fungus, branching of T. vaccinum was reduced after SA application. Instead, the mycelium explored a larger surface area aiding in nutrient acquisition. Root-derived SA could thus re-direct $T$. vaccinum growth towards soil exploration. At earlier stages, SA close to the root might increase directional growth towards the root. Since the fungus could form SA, a role in re-directing growth might also be possible in saprotrophic growth. The biosynthetic polyketide synthase shows similarities to a 6-methyl salicylic acid synthase of Penicillium griseofulvum (Spencer and Jordan 1992).

ABA was not found in the spruce exudate, but its presence in root apices is well documented (Dunstan and Bock 1997). It positively influences phosphate utilization and nitrate uptake (Ullrich and Kunz 1984) as well as water balance in plants (Bradford 1983; Xu et al. 2013). We found ABA in T. vaccinum axenic cultures and in the soil samples. SA has been shown to enhance hyphal branching in AM mycorrhiza (Herrera-Medina et al. 2007). Changes in SA/ ABA levels in the rhizosphere could modulate growth rate and branching in $T$. vaccinum and thus support adaptation to fluctuating environmental conditions and facilitate mycorrhization. The production in axenic fungal cultures would make the substances, known only for their phytohormone functions, to be systemic signals in fungi during growth in soil, which has not yet been reported.

In conclusion, the ectomycorrhizosphere of $T$. vaccinum and $P$. abies was shown to be a place of concomitant 
production of phytohormones as well as volatiles which then are available for exchange of dissolved or volatile signals. Both, VOCs and phytohormones could be shown to be produced by both partners, and for both mycorrhizal partners, a reaction to the compounds was verified. This establishes cross-kingdom signal exchange that might be necessary for optimal development of both symbionts in a fine-tuned manner. The biosynthesis by the basidiomycete fungus evidences co-evolution in this mutual symbiosis. In addition, the ectomycorrhizal microbiome modulates production. Appearance of the same molecules like SA, IAA, geosmin, or limonene in evolutionarily unrelated organisms stimulates the discussion to an "interkingdom language" in the ectomycorrhizosphere.

Acknowledgments We are grateful to Anne Spranger for support with mycorrhiza co-cultures. We thank Vincent Kessler and Atif Ahmad for support in root cross-sections, qRT-PCR, and RNA-Seq analyses. We thank S. Bhattacharya and I. Baldwin (MPI for Chemical Ecology, Jena, Germany) for help with the photoacoustic measurements.

Funding Open Access funding enabled and organized by Projekt DEAL. This research was financially supported by the SFB ChemBioSys, the International Max-Planck Research School (IMPRS), the Friedrich Schiller University, and the Jena School of Microbial Communication (JSMC).

\section{Compliance with ethical standards}

Conflict of interest The authors declare that they have no conflict of interest.

Open Access This article is licensed under a Creative Commons Attribution 4.0 International License, which permits use, sharing, adaptation, distribution and reproduction in any medium or format, as long as you give appropriate credit to the original author(s) and the source, provide a link to the Creative Commons licence, and indicate if changes were made. The images or other third party material in this article are included in the article's Creative Commons licence, unless indicated otherwise in a credit line to the material. If material is not included in the article's Creative Commons licence and your intended use is not permitted by statutory regulation or exceeds the permitted use, you will need to obtain permission directly from the copyright holder. To view a copy of this licence, visit http://creativecommons.org/licenses/by/4.0/.

\section{References}

Agerer R (1987-2002) Colour Atlas of Ectomycorrhizae, EinhornVerlag, Schwäbisch Gmünd

Agger S, Lopez-Gallego F, Schmidt-Dannert C (2009) Diversity of sesquiterpene synthases in the basidiomycete Coprinus cinereus. Mol Microbiol 72:1307-1308. https://doi.org/10.111 1/j.1365-2958.2009.06743.x

Arnerup J, Nemesio-Gorriz M, Lunden K, Asiegbu FO, Stenlid J, Elfstrand M (2013) The primary module in Norway spruce defence signalling against $H$. annosum s.l. seems to be jasmonate-mediated signalling without antagonism of salicylate-mediated signalling. Planta 237:1037-1045
Asiimwe T, Krause K, Schlunk I, Kothe E (2012) Modulation of ethanol stress tolerance by aldehyde dehydrogenase in the mycorrhizal fungus Tricholoma vaccinum. Mycorrhiza 22:471-484

Audenaert K, Pattery T, Cornelis P, Höfte M (2002) Induction of systemic resistance to Botrytis cinerea in tomato by Pseudomonas aeruginosa 7NSK2: role of salicylic acid, pyochelin, and pyocyanin. Mol Plant Microbe Interact 15:1147-1156

Bäck J, Aaltonen H, Hellén H, Kajos MK, Patokoski J, Taipale R, Pumpanen J, Heinonsalo J (2010) Variable emissions of microbial volatile organic compounds (MVOCs) from root-associated fungi isolated from Scots pine. Atmos Environ 44:3651-3659

Bentley R, Meganathan R (1981) Geosmin and methylisoborneol biosynthesis in streptomycetes. Evidence for an isoprenoid pathway and its absence in non-differentiating isolates. FEBS Lett 125(2):220-222

Besserer A, Puech-Pagès V, Kiefer P, Gomez-Roldan V, Jauneau A, Roy S, Portais JC, Roux C, Bécard G, Sejalon-Delmas N (2006) Strigolactones stimulate arbuscular mycorrhizal fungi by activating mitochondria. PLOS Biol 4:e226

Bradford KJ (1983) Water relations and growth of the flacca tomato mutant in relation to abscisic acid. Plant Physiol 72:251-255

Bukvicki DR, Tyagi AK, Gottardi DG, Veljic MM, Jankovic SM, Guerzoni ME, Marin PD (2013) Assessment of the chemical composition and in vitro antimicrobial potential of extracts of the liverwort Scapania aspera. Nat Prod Commun 8:1313-1316

Carpenter-Boggs L, Loynachan TE, Stahl PD (1995) Spore germination of Gigaspora margarita stimulated by volatiles of soilisolated actinomycetes. Soil Biol Biochem 27:1445-1451

Davies PJ (2010) Plant Hormones. In: Davies P (ed) The plant hormones: their nature, occurrence, and functions. Springer, Dordrecht, pp 1-15

Dempsey DA, Vlot AC, Wildermuth MC, Klessig DF (2011) Salicylic Acid Biosynthesis and Metabolism. TAB e0156. doi: https ://doi.org/10.1199/tab.0156

Ditengou FA, Müller A, Rosenkranz M, Felten J, Lasok H, van Doorn MM, Legué V, Palme K, Schnitzler J-P, Polle A (2015) Volatile signalling by sesquiterpenes from ectomycorrhizal fungi reprogrammes root architecture. Nat Commun 6:6279

Dor E, Joel DM, Kapulnik Y, Koltai H, Hershenhorn J (2011) The synthetic strigolactone GR24 influences the growth pattern of phytopathogenic fungi. Planta 234:419-427

Duetz WA, Bouwmeester H, van Beilen JB, Witholt B (2003) Biotransformation of limonene by bacteria, fungi, yeasts, and plants. Appl Microbiol Biotechnol 61:269-277

Dunstan DI, Bock CA (1997) Abscisic acid [(+)-ABA] content in white spruce somatic embryo tissues related to concentration of fed ABA. J Plant Physiol 150:691-696

Dupuy HP, Flick GJ, St. Angelo AJ, Sumrell G (1986) Analysis for trace amounts of geosmin in water and fish. J Am Oil Chem Soc 63:905-908. https://doi.org/10.1007/bf02540925

Effmert U, Kalderas J, Warnke R, Piechulla B (2012) Volatile mediated interactions between bacteria and fungi in the soil. J Chem Ecol 38:665-703

Erdmann S, Freihorst D, Raudaskoski M, Schmidt-Heck W, Jung E-M, Senftleben D, Kothe E (2012) Transcriptome and functional analysis of mating in the basidiomycete Schizophyllum commune. Eukaryot Cell 11:571-589. https://doi.org/10.1128/ ec.05214-11

Fäldt J, Jonsell M, Nordlander G, Borg-Karlson A-K (1999) Volatiles of bracket fungi Fomitopsis pinicola and Fomes fomentarius and their functions as insect attractants. J Chem Ecol 25:567-590

Felten J, Kohler A, Morin E, Bhalerao RP, Palme K, Martin F, Ditengou FA, Legué V (2009) The ectomycorrhizal fungus Laccaria bicolor stimulates lateral root formation in poplar and Arabidopsis through auxin transport and signaling. Plant Physiol 51:1991-2005 
Felten J, Martin F, Legué V (2012) Signalling in ectomycorrhizal symbiosis. In: Perotto $S$, Baluška F (eds) Signaling and Communication in Plant Symbiosis. Springer, Berlin Heidelberg, pp 123-142

Gális I, Gaquerel E, Pandey SP, Baldwin IT (2009) Molecular mechanisms underlying plant memory in JA-mediated defence responses. Plant Cell Environ 32:617-627

Gea L, Normand L, Vian B, Gay G (1994) Structural aspects of ectomycorrhiza of Pinus pinaster (Ait.) Sol. formed by an IAA-overproducer mutant of Hebeloma cylindrosporum Romagnési. New Phytol 128:659-670

Gerber N, Lechevalier H (1965) Geosmin, an earthy-smelling substance isolated from actinomycetes Appl Microbiol 13:935-938

Graham J, Linderman R (1980) Ethylene production by ectomycorrhizal fungi, Fusarium oxysporum f. sp. pini, and by aseptically synthesized ectomycorrhizae and Fusarium-infected Douglas-fir roots. Can J Microbiol 26:1340-1347

Groen SC, Whiteman NK (2014) The evolution of ethylene signaling in plant chemical ecology. J Chem Ecol 40:700-716

Guranowski A, Miersch O, Staswick PE, Suza W, Wasternack C (2007) Substrate specificity and products of side-reactions catalyzed by jasmonate:amino acid synthetase (JAR1). FEBS Lett 581:815-820

Hause B, Mrosk C, Isayenkov S, Strack D (2007) Jasmonates in arbuscular mycorrhizal interactions. Phytochemistry 68:101-110

Henke C, Kunert M, Veit D, Kunert G, Krause K, Kothe E, Boland W (2015) Analysis of volatiles from Picea abies triggered by belowground interactions. Environ Exp Bot 110:56-61

Henke C, Jung E-M, Kothe E (2015) Hartig' net formation of Tricholoma vaccinum-spruce ectomycorrhiza in hydroponic cultures. Environ Sci Pollut Res 22:19394-19399

Henke C, Jung E-M, Voit A, Kothe E, Krause K (2016) Dehydrogenase genes in the ectomycorrhizal fungus Tricholoma vaccinum: A role for Ald1 in mycorrhizal symbiosis. J Basic Microbiol 56(2):162-174

Herrera-Medina MJ, Steinkellner S, Vierheilig H, Ocampo Bote JA, García Garrido JM (2007) Abscisic acid determines arbuscule development and functionality in the tomato arbuscular mycorrhiza. New Phytol 175:554-564

Jiang J, Cane DE (2008) Geosmin biosynthesis. Mechanism of the fragmentation-rearrangement in the conversion of germacradienol to geosmin. J Am Chem Soc 130(2):428-429. https://doi. org/10.1021/ja077792i

Jiang J, He X, Cane DE (2006) Geosmin biosynthesis. Streptomyces coelicolor germacradienol/ germacrene D synthase converts farnesyl diphosphate to geosmin. J Am Chem Soc 128(25):81288129. https://doi.org/10.1021/ja062669x

Jiang J, He X, Cane DE (2007) Biosynthesis of the earthy odorant geosmin by a bifunctional Streptomyces coelicolor enzyme. Nature Chem Biol 3(11):711-715. https://doi.org/10.1038/nchem bio. 2007.29

Katoh K, Standley DM (2013) MAFFT Multiple sequence alignment software version 7: improvements in performance and usability. Mol Biol Evol 30(4):772-780. https://doi.org/10.1093/molbev/ mst010

Katoh K, Toh H (2008) Recent developments in the MAFFT multiple sequence alignment program. Brief Bioinformatics 9(4):286-298. https://doi.org/10.1093/bib/bbn013

Kikuchi T, Kadota S, Suehara H, Nishi A, Tsubaki K (1981) Odorous metabolites of a fungus Chaetomium globosum KINZE ex FR. Identification of geosmin, a musty-smelling compound. Chem Pharm Bull 29(6):1782-1784

Kishimoto K, Matsui K, Ozawa R, Takabayashi J (2007) Volatile 1-octen-3-ol induces a defensive response in Arabidopsis thaliana. J Gen Plant Pathol 73:35-37

Kottke I, Guttenberger M, Hampp R, Oberwinkler F (1987) An in vitro method for establishing mycorrhizae on coniferous tree seedlings. Trees 1:191-194
Krause K, Kothe E (2006) Use of RNA fingerprinting to identify fungal genes specifically expressed during ectomycorrhizal interaction. J Basic Microb 46:387-399

Krause K, Henke C, Asiimwe T, Ulbricht A, Klemmer S, Schachtschabel D, Boland W, Kothe E (2015) Indole-3-acetic acid biosynthesis, secretion, and its morphological effects on Tricholoma vaccinum-spruce ectomycorrhiza. Appl Environ Microbiol 81(20):7003-7011

Krokene P, Nagy NE, Solheim H (2008) Methyl jasmonate and oxalic acid treatment of Norway spruce: anatomically based defense responses and increased resistance against fungal infection. Tree Physiol 28:29-35

Laurans F, Pepin R, Gay G (2001) Fungal auxin overproduction affects the anatomy of Hebeloma cylindrosporum-Pinus pinaster ectomycorrhizas. Tree Physiol 21:533-540

Lu G, Edwards CG, Fellman JK, Mattinson DS, Navazio J (2003) Biosynthetic origin of geosmin in red beets (Beta vulgaris L). J Agric Food Chem 51:1026-1029

Luo ZB, Janz D, Jiang X, Göbel C, Wildhagen H, Tan Y, Rennenberg H, Feussner I, Polle A (2009) Upgrading root physiology for stress tolerance by ectomycorrhizas: insights from metabolite and transcriptional profiling into reprogramming for stress anticipation. Plant Physiol 151:1902-1917

Macías-Rodríguez L, Contreras-Cornejo HÁ, López-Bucio JS, LópezBucio J (2015) Recent advancements in the role of volatile organic compounds from fungi. In: Sreenivasaprasad S (ed) Fungal Biomolecules: Sources. Applications and Recent Developments, Wiley, Chichester, pp 87-99

Mattheis JP, Roberts RG (1992) Identification of geosmin as a volatile metabolite of Penicillium expansum. Appl Environ Microbiol 58:3170-3172

Medina JH, Gagnon H, Piché Y, Ocampo JA, Garrido JMG, Vierheilig $\mathrm{H}$ (2003) Root colonization by arbuscular mycorrhizal fungi is affected by the salicylic acid content of the plant. Plant Sci 164:993-998

Miersch O, Günther T, Fritsche W, Sembdner G (1993) Jasmonates from different fungal species. Nat Prod Lett 2:293-299

Moffatt BA, Weretilnyk EA (2001) Sustaining S-adenosyl-L-methionine-dependent methyltransferase activity in plant cells. Physiol Plant 113:435-442

Müller A, Faubert P, Hagen M, zu Castell W, Polle A, Schnitzler J-P, Rosenkranz M (2013) Volatile profiles of fungi-chemotyping of species and ecological functions. Fungal Genet Biol 54:25-33

Notredame C, Higgins DG, Heringa J (2000) T-coffee: a novel method for fast and accurate multiple sequence alignment11Edited by. J Thornton J Mol Biol 302(1):205-217. https://doi.org/10.1006/ jmbi.2000.4042

Omura H, Kuwahara Y, Tanabe T (2002) 1-Octen-3-ol together with geosmin: new secretion compounds from a polydesmid millipede Niponia nodulosa. J Chem Ecol 28:2601-2612. https://doi. org/10.1023/A:1021400606217

Quin MB, Flynn CM, Schmidt-Dannert C (2014) Transversing the fungal terpenome. Nat Prod Rep 31(10):1449-1473 32:1449. doi: https://doi.org/10.1039/c4np00075g

Persson M, Sjödin K, Borg-Karlson AK, Norin T, Ekberg I (1996) Relative amounts and enantiomeric compositions of monoterpene hydrocarbons in xylem and needles of Picea abies. Phytochemistry 42:1289-1297

Pfaffl MW (2001) A new mathematical model for relative quantification in real-time RT-PCR. Nucleic Acids Res 29:e45-e45

Raudaskoski M, Kothe E (2015) Novel findings on the signal exchange in arbuscular and ectomycorrhizal symbioses. Mycorrhiza 25:243-252

Read DJ, Leake JR, Perez-Moreno J (2004) Mycorrhizal fungi as drivers of ecosystem processes in heathland and boreal forest biomes. Can J Bot 82:1243-1263 
Rieger S (1995) Veränderungen des Monoterpenspektrums in verletzten Fichtenwurzeln und ihre potentielle Bedeutung für die Resistenz gegenüber Heterobasidion annosum. Eur J Forest Pathol 25:367-380

Sammer D, Krause K, Gube M, Wagner K, Kothe E (2016) Hydrophobins in the life cycle of the ectomycorrhizal basidiomycete Tricholoma vaccinum. PLoS ONE 11:e0167773

Scagel CF, Linderman RG (1998) Relationships between differential in vitro indole-acetic acid or ethylene production capacity by ectomycorrhizal fungi and conifer seedling responses in symbiosis. Symbiosis 24:13-34

Schäfer M, Brütting C, Baldwin IT, Kallenbach M (2016) Highthroughput quantification of more than 100 primary- and secondary-metabolites, and phytohormones by a single solidphase extraction based sample preparation with analysis by UHPLC-HESI-MS/MS. Plant Methods 12:30

Schlunk I, Krause K, Wirth S, Kothe E (2015) A transporter for abiotic stress and plant metabolite resistance in the ectomycorrhizal fungus Tricholoma vaccinum. Environ Sci Pollut Res 22:19384-19393

Shaw JJ, Berbasova T, Sasaki T, Jefferson-George K, Spakowicz DJ, Dunican BF, Portero CE, Narváez-Trujillo A, Strobel SA (2015) Identification of a fungal 1,8-cineole synthase from Hypoxylon sp. with specificity determinants in common with the plant synthases. J Biol Chem 290(13):8511-8526

Siddique MH, Liboz T, Bacha N, Puel O, Mathieu F, Lebrihi A (2012) Characterization of a cytochrome $\mathrm{P} 450$ monooxygenase gene involved in the biosynthesis of geosmin in Penicillium expansum. Afr J Microbiol Res 6:4122-4127

Spencer JB, Jordan PM (1992) Purification and properties of 6-methylsalicylic acid synthase from Penicillium patulum. Biochem $\mathrm{J}$ 288:839-846

Spiteller D, Jux A, Piel J, Boland W (2002) Feeding of [5,5-2H(2)]1-desoxy-D-xylulose and $[4,4,6,6,6-2 \mathrm{H}(5)]$-mevalolactone to a geosmin-producing Streptomyces sp. and Fossombronia pusilla. Phytochemistry 61:827-834. https://doi.org/10.1016/s0031 -9422(02)00282-0

Splivallo R, Fischer U, Göbel C, Feussner I, Karlovsky P (2009) Truffles regulate plant root morphogenesis via the production of auxin and ethylene. Plant Physiol 150:2018-2029

Taki N, Sasaki-Sekimoto Y, Obayashi T, Kikuta A, Kobayashi K, Ainai T, Yagi K, Sakurai N, Suzuki H, Masuda T (2005) 12-oxo-phytodienoic acid triggers expression of a distinct set of genes and plays a role in wound-induced gene expression in Arabidopsis. Plant Physiol 139:1268-1283

Timonen S, Marschner P (2006) Mycorrhizosphere concept. In: Mukerji JG, Manoharachary C, Singh J (eds.) Microbial activity in the rhizoshere. Soil Biology. 7. Springer, Berlin New York, pp. $155-72$

Ullrich WR, Kunz G (1984) Effect of abscisic acid on nitrate uptake, respiration and photosynthesis in green algae. Plant Sci Lett 37:9-14

Wagner K, Krause K, Gallegos-Monterrosa R, Sammer D, Kovács ÁT, Kothe E (2019) The ectomycorrhizospheric habitat of Norway spruce and Tricholoma vaccinum: promotion of plant growth and fitness by a rich microorganismic community. Front Microbiol 10:307. https://doi.org/10.3389/fmicb.2019.00307

Wu J, Hettenhausen C, Meldau S, Baldwin IT (2007) Herbivory rapidly activates MAPK signaling in attacked and unattacked leaf regions but not between leaves of Nicotiana attenuata. Plant Cell 19:1096-1122

Xu W, Jia L, Shi W, Liang J, Zhou F, Li Q, Zhang J (2013) Abscisic acid accumulation modulates auxin transport in the root tip to enhance proton secretion for maintaining root growth under moderate water stress. New Phytol 197:139-150 